\title{
Rejection Sensitivity and Marital Adjustment among Military Spouses during Deployments
}

\author{
E. C. Hurley ${ }^{1}$, Tiffany Field ${ }^{1,2}$, Debra Bendell-Estoff ${ }^{1}$ \\ ${ }^{1}$ Fielding Graduate University, Santa Barbara, USA \\ ${ }^{2}$ Medical School, University of Miami, Miami, USA \\ Email: tfield@fielding.edu
}

Received March 20 $0^{\text {th }}, 2012$; revised April 24 ${ }^{\text {th }}, 2012$; accepted May $21^{\text {st }}, 2012$

\begin{abstract}
This research examined the relationship between rejection sensitivity and marital adjustment. The Adult Rejection Sensitivity Questionnaire (ARSQ) and the Revised Dyadic Adjustment Scale (RDAS) were given to address this question among a sample of 129 spouses of individuals currently deployed on military missions in Iraq or Afghanistan. Other potentially confounding variables were examined including gender, age, education, number of times married, number of children in the household, number of previous deployments, and number of months separated during the current combat deployment. Rejection sensitivity and number of deployments contributed to $34 \%$ of the variance on relationship adjustment.
\end{abstract}

Keywords: Rejection Sensitivity; Military; Marital Adjustment

\section{Introduction}

Operation Iraqi Freedom (OIF) and Operation Enduring Freedom (OEF) have provided opportunities for research on problems associated with deployments (Karney \& Crown, 2007). Much of the current research on military personnel focuses on individual disorders such as depression and posttraumatic stress disorder. Recognition of the importance of military family problems has led to family research. The current research was designed to study military spouses' perceptions of rejection sensitivity and marital adjustment during deployments along with other potentially confounding effects on relationships including gender, age, education, number of marriages, number of children, number of previous deployments, and number of months separated during current combat deployment.

\section{Marital Adjustment during Deployment}

Some research has indicated that war-related separations increased marital instability (Frey-Wouters \& Laufer, 1986; Gimbel \& Booth, 1994; Laufer \& Gallops, 1985; Stellman, Stellman, \& Sommer, 1988). Other data have indicated that military separations were negatively related to marital satisfaction, although these data were limited to only a $13 \%$ response (Burrell, Adams, Durand, \& Castro's, 2006). In contrast, longitudinal data comparing Vietnam veterans and nonveterans found no group differences in divorce rates (Call \& Teachman, 1991; Card, 1983). Some have even reported positive effects (Karney \& Crown's, 2007). That study suggested that marriages may be positively influenced by military service due to the resources and benefits available to military families, particularly when not exposed to combat. These benefits included extra pay, child care and health care, family support programs, parenting and marriage programs. Still others have focused on the risk and resiliency factors that influenced family stability during deployments (Sheppard, Malatras, \& Israel, 2010). However, anecdotal reports of rejection sensitivity in the remaining-at-home spouses of those who have been deployed highlight the question of its effects on the marital relationship. The current study addressed the relationship between rejection sensitivity and marital relationship adjustment in a sample of military spouses.

\section{A Model for Understanding Rejection Sensitivity}

One theory on rejection sensitivity suggests that expectations of rejection interact with the specifics of the situation (marital separation due to deployment) (Freitas \& Downey, 1998; Mischel \& Ayduk, 2002). A person who enters a romantic relationship with anxious expectations of rejection is predisposed to anticipate insensitive behavior from her/his spouse, especially under stressful conditions.

Based on this model, military spouses may experience rejecttion sensitivity in the following way. If the situation (such as interpreting the spouse's email) engenders an ambiguous or negative response from the deployed spouse, that response could be interpreted as uncaring behavior on the part of the deployed spouse. The spouses can scan interpersonal situations looking for cues as they anxiously expect to find evidence to substantiate their fear of abandonment. They then tend to become excessively concerned regarding whether or not they are loved. During deployments, communication problems can intensify the ambiguity. The stress of the situation enhances the capacity for negative interpretations. This process can trigger a cascade of feelings of anger, rage and resentment as the fear of abandonment intensifies. Controlling and coercive behaviors may result. Fears of rejection often lead to a self-fulfilling prophecy. One partner responds with emotional reactivity, generated by an interpreted uncaring response from the spouse passively seeking reassurance. Emotional distancing may result, which is likely to escalate as the partner moves into a protective mode. The escalation may then lead to an extra-marital affair or planning for divorce.

Downey and colleagues have demonstrated that childhood rejection experiences can lead to later rejection sensitivity (Feld- 
man \& Downey, 1994). Anticipatory rejection in relationships is perceived as originating in a parent's rejection of a child's needs, causing the child to become sensitive to rejection. The model suggests that these individuals may enter relationships with a propensity to expect rejection from significant others. During stressful times, they are especially likely to 1) perceive rejection by the partner's insensitive or ambiguous behaviors, 2) feel insecure about the relationship, and 3) respond to perceived rejection with hostility, diminished support, or jealous, controlling behavior (Downey \& Feldman, 1996). When such responses are unjustified and exaggerated, they are likely to erode even a committed partner's satisfaction with the relationship.

\section{Rejection Sensitivity Research Applications}

Early rejection sensitivity research operationalized and validated the construct of rejection sensitivity and demonstrated how it impacted intimate relationships using a self-report scale called the Rejection Sensitivity Questionnaire (RSQ) (Downey \& Feldman, 1996). In this study on rejection sensitivity, individuals who anxiously expected rejection by a significant other tended to hurtful intent to a new romantic partner's insensitive behavior (Downey \& Feldman, 1996). This response was not induced by the other variables measured including social anxiety, social avoidance, attachment style, self-esteem, neuroticism, and introversion. The results also suggested that the rejectionsensitive individuals were less satisfied with their relationships and perceived their partner to be less satisfied as well. Another study by Downey suggested that when both partners rate high rejection sensitivity, the relationship is likely to end sooner (Purdie \& Downey, 2000).

Most of these studies on rejection sensitivity focused on single undergraduate students. The current study extended this research area by examining rejection sensitivity among military spouses and how rejection sensitivity relates to relationship adjustment. Based on the separate literatures of rejection sensitivity and relationship adjustment, these variables were expected to be negatively related.

\section{Method}

\section{Design}

A survey monkey was used to assess rejection sensitivity and relationship adjustment among spouses of army personnel who were deployed to a combat zone, (either Afghanistan or Iraq). Rejection sensitivity and relationship adjustment were surveyed among the stay-at-home military spouses of both genders. Rejection-sensitive persons were expected to have low relationship adjustment. Potentially confounding variables including gender, age, education, number of marriages, number of children in the household, number of previous deployments, and total separation time during current deployment were entered along with rejection sensitivity scores into a correlation analysis and a regression analysis on the Revised Dyadic Adjustment Scale (RDAS) scores.

\section{Participants}

This non-clinical sample of spouses of army personnel (rank E-2 to E-7) was recruited at a shopping mall in a military base town. The sample was comprised of 129 participants (see Table
1). Everyone enrolled in the study was able to complete the survey. The participants were $94 \%$ female, and their ages ranged from 19 to 50, with $57 \%$ being between 21 and 29 years old. The participants had 12 to 20 years of education. Seventyseven percent of the participants were in their first marriage, $11 \%$ had one previous military marriage and $12 \%$ had $2-5$ previous marriages. Seventy-five percent were married to spouses who had no previous marriages while $25 \%$ were married to spouses who were married one or two times before. The length of the current marriages ranged from .3 to 19 years with an average of 5 years. The average number of children the participants had in their home was 1.5 .

The number of military deployments ranged from one to eight. Eighty-eight percent had between one and four military deployment separations while $56 \%$ had no other separations, and $44 \%$ had between one and 39 other separations. The total time that spouses were separated due to military deployments ranged from 1 to 96 months with a mean of 32 months.

\section{Procedure}

A heavily trafficked central area was selected within the shopping mall for the survey. Two laptop computers with wireless connections to the Survey Monkey website were placed on the table, and two folding chairs were placed at the table for participants' seating during data collection. A reading rug with books and games was provided for the children of the participants. A sign described the research project. An administrative assistant was present at the recruiting table to respond to questions regarding the research project. The assistant waited for potential participants to approach the table as a response to reading the sign. Participation was both voluntary and confidential, although participants were offered $\$ 20$ as an incentive and the opportunity to enter a $\$ 200$ lottery drawing to be conducted after the study was completed. An informed consent form was provided for each participant. After completing the Survey Monkey questionnaires, the assistant debriefed the participants.

Table 1.

Demographic and assessment scale values.

\begin{tabular}{lcccc}
\hline Variable & Minimum & Maximum & Mean & SD \\
\hline Age & 19.0 & 50.0 & 28.61 & 5.91 \\
Education & 11.9 & 20.0 & 13.95 & 1.99 \\
Current marriage (yrs.) & .3 & 19.0 & 5.05 & 4.06 \\
$\begin{array}{l}\text { Times married } \\
\text { Number of }\end{array}$ & 1.0 & 5.0 & 1.31 & .65 \\
$\begin{array}{l}\text { Deployments } \\
\text { Times spouse } \\
\text { married }\end{array}$ & 1.0 & 8.0 & 2.62 & 1.55 \\
$\begin{array}{l}\text { Total time } \\
\text { separated (mos.) }\end{array}$ & 1.0 & 3.0 & 1.30 & .57 \\
$\begin{array}{l}\text { Current separation (mos.) } \\
\text { Number of children }\end{array}$ & 1.0 & 15.0 & 3.47 & 3.33 \\
$\begin{array}{l}\text { in home } \\
\text { Adult rejection } \\
\text { sensitivity }\end{array}$ & 0 & 9.0 & 1.50 & 1.41 \\
\begin{tabular}{l} 
Dyadic adjustment \\
\hline
\end{tabular} & 1.11 & 22.55 & 8.38 & 4.94 \\
& 11.0 & 65.0 & 47.80 & 10.23 \\
\hline
\end{tabular}




\section{Questionnaires}

The questionnaires used in this research included the Adult Rejection Sensitivity Questionnaire (ARSQ), the Revised Dyadic Adjustment Scale (RDAS), and the Participant Information Form (PIF). The ARSQ and RDAS were presented in a counterbalanced order. The PIF was used to provide information on potentially confounding variables.

The Adult Rejection Sensitivity Questionnaire (ARSQ) (Downey, Berenson, \& Kang, 2006). The Adult Rejection Sensitivity Questionnaire (ARSQ) was developed for studies of adult samples. It was normed using a sample of 685 adults who completed the questionnaire over the internet. Correlations with other measures (self-esteem, attachment, etc.) were similar to those found with the earlier student RSQ version. The ARSQ has high internal reliability (alpha $=.83$ ), and all items on the questionnaire had $>.30$ correlation coefficients. A high testretest reliability was noted as well $(.83, p<.001)$.

The Adult Rejection Sensitivity Questionnaire (ARSQ) includes a list of 9 hypothetical situations. Each situation has two questions for a total of 18 answers. Examples of these items are 1) After a bitter argument, you call or approach your significant other because you want to make up; and 2) Lately you've been noticing some distance between yourself and your significant other and you ask him/her if there is something wrong. The first question for each situation measures the degree of anxiety regarding the potential outcome on a 6-point scale ranging from 1 (very unconcerned) to 6 (very concerned). The second question for each of the nine situations asks the participant to indicate the likelihood of the other person responding with acceptance on a similar 6-point scale. Anticipated rejection is noted by lower scores. The score for each of the nine situations is calculated by weighting the expected likelihood of rejection by how concerned or anxious the participant recorded his or her response. The score on expectancy of acceptance is reversed as a means of indexing the expectancy of rejection (expectancy of rejection $=7-$ expectancy of acceptance). Next, the reversed score is multiplied by the score noted for the degree of concern or anxiety. The total rejection sensitivity score for each participant was determined by summing the rejection sensitivity for each situation and dividing by 9 (the total number of situations).

Revised Dyadic Adjustment Scale (RDAS) (Busby, Christensen, Crane, \& Larson, 1995). The Dyadic Adjustment Scale (DAS) was originally developed by Spanier $(1976,1986)$ as an instrument with four subscales measuring couples' relationship adjustment including: 1) consensus on matters of importance, 2) dyadic satisfaction, 3) dyadic cohesion, and 4) affectional expression. In keeping with Spanier's (1976) original intent, the RDAS includes 3 subscales (14 items) of consensus, satisfaction, and cohesion. Factor analysis provided evidence for the construct validity of the revised version of the instrument (Busby et al., 1995). Criterion validity was demonstrated by discriminant function analyses. Internal consistency was high (alpha $=.79)($ Crane et al., 1990).

Demographic questionnaire. The spouses of deployed military personel also completed a demographic questionnaire on potential covariates. These included gender, age, education, number of marriages, number of children in household, number of deployments and total months of current deployment.

\section{Results}

\section{Correlation Analysis}

A Pearson correlation analysis was conducted (Table 2). The

Table 2.

Matrix of pearson's correlation coefficients.

\begin{tabular}{|c|c|c|c|c|c|c|c|c|c|c|c|c|}
\hline & RDAS & ARSQ & Age & Education & $\begin{array}{c}\text { Times } \\
\text { Married }\end{array}$ & $\begin{array}{l}\text { Current } \\
\text { Marriage }\end{array}$ & $\begin{array}{c}\text { Times } \\
\text { Spouse }\end{array}$ & $\begin{array}{l}\text { Number of } \\
\text { Children }\end{array}$ & $\begin{array}{l}\text { Average } \\
\text { Child Age }\end{array}$ & $\begin{array}{l}\text { Deployment } \\
\text { Separations }\end{array}$ & $\begin{array}{c}\text { Other } \\
\text { Separations }\end{array}$ & $\begin{array}{l}\text { Total Time } \\
\text { Separated }\end{array}$ \\
\hline ARSQ & -.52 & & & & & & & & & & & \\
\hline Gender & .06 & .05 & & & & & & & & & & \\
\hline Age & .03 & -.00 & & & & & & & & & & \\
\hline Education & -.07 & -.04 & .19 & & & & & & & & & \\
\hline Times Married & -.07 & -.09 & .35 & .04 & & & & & & & & \\
\hline $\begin{array}{l}\text { Current Marriage } \\
\text { Length }\end{array}$ & -.10 & -.03 & .39 & .12 & -.12 & & & & & & & \\
\hline $\begin{array}{c}\text { Times Spouse } \\
\text { Married }\end{array}$ & .05 & -.06 & .41 & .14 & .34 & -.08 & & & & & & \\
\hline $\begin{array}{l}\text { Number of } \\
\text { Children }\end{array}$ & -.06 & -.02 & .27 & -.32 & .01 & .38 & -.01 & & & & & \\
\hline $\begin{array}{l}\text { Average Child } \\
\text { Age }\end{array}$ & .11 & -.04 & .69 & .18 & .29 & .36 & .20 & .46 & & & & \\
\hline $\begin{array}{c}\text { \# of } \\
\text { Deployments }\end{array}$ & -.27 & .08 & .34 & .17 & .31 & .09 & .23 & .02 & .12 & & & \\
\hline $\begin{array}{c}\text { Other } \\
\text { Separations }\end{array}$ & -.11 & -.02 & .06 & .20 & .16 & .10 & -.08 & .03 & .17 & .10 & & \\
\hline $\begin{array}{l}\text { Total Time } \\
\text { Separated }\end{array}$ & -.20 & .07 & .19 & .25 & .20 & .14 & .19 & -.05 & .07 & .71 & .42 & \\
\hline $\begin{array}{c}\text { Current } \\
\text { Separation }\end{array}$ & .04 & -.005 & -.09 & .08 & -.05 & .01 & -.12 & -.14 & -.09 & -.11 & .05 & .10 \\
\hline
\end{tabular}

$p<.05$ for those coefficients in bold; RDAS = Revised Dyadic Adjustment Scale; ARSQ = Adult Rejection Sensitivity Questionaire. 
RDAS scores were negatively correlated with the ARSQ scores $(\mathrm{r}=-.52)$, the number of military deployment separations $(\mathrm{r}=$ $-.27)$ and the total time separated $(r=-.20)$. Higher rejection sensitivity scores, more deployment separations and the total time separated were associated with lower marital adjustment scores.

The extent to which the zero-order negative correlation between the composite ARSQ and RDAS scores $(\mathrm{r}=-.52)$ was influenced by the potentially confounding/mediating variables was determined by partial correlation analysis. None of the partial correlation coefficients decreased when the correlation between ARSQ and RDAS was controlled for gender, age, education, times married, current marriage length, times spouse married, number of children, average child age, deployment separations, other separations, total time separated, or current separation time. Thus, the negative correlation between ARSQ and RDAS was not mediated by the potentially confounding variables.

\section{Stepwise Multiple Linear Regression Analysis}

The stepwise multiple linear regression analysis also controlled for the potential confounding variables including gender, age, education, times married, current marriage length, times spouse married, number of children, average child age, other separations, total time separated, and current separation time. The $t$ statistics indicated that these variables were not significant predictors of the variability in the RDAS scores at $p>.05$ (Table 3).

The stepwise regression retained the ARSQ scores and the number of military deployments in the model (Table 3). The $t$ statistics indicated that these variables were significant predictors of the RDAS scores at $p=.05$. The $\mathrm{R}^{2}$ adjusted value indicated that $34 \%$ of the variance in the RDAS scores was accounted for by the ARSQ scores and the number of deployments. This proportion was statistically significant, indicated by $F(2,89)=24.57, p<.001$, and reflected by a medium size effect according to the criteria of Cohen (1992). The negative signs of the regression coefficients implied that greater rejection sensitivity and more deployments predicted a lower level of marital adjustment.

\section{Discussion}

This research suggests that rejection sensitivity affected military spouses' relationship adjustment. Further, the total number of deployments had a greater impact on relationship adjustment than the immediate deployment separation. This finding is consistent with those of Burrell et al. (2006) who reported that military deployments were negatively related to marital satisfaction.

Downey and Feldman (1996) noted that those who score high on rejection sensitivity have a propensity to anxiously expect rejection, readily perceive negative signals (both verbal and non-verbal), and overreact to their spouses while in their relationships. The spouses' negative reactions can elicit further rejection from their partners as a precursor to ending the relationship (Downey et al., 1998). Potential confounding variables did not affect relationship adjustment in this study including gender, age, education, number of marriages, number of children in the household, or number of months currently separated due to deployment. But the total number of deployments was
Table 3.

Stepwise regression analysis on marital adjustment.

\begin{tabular}{|c|c|c|c|c|c|c|}
\hline \multirow{2}{*}{ Variables } & \multicolumn{2}{|c|}{$\begin{array}{l}\text { Unstandardized } \\
\text { Coefficients }\end{array}$} & \multirow{2}{*}{$\begin{array}{c}\begin{array}{c}\text { Standardized } \\
\text { Coefficients }\end{array} \\
\beta \text { Weights }\end{array}$} & \multirow{2}{*}{$t$} & \multirow{2}{*}{$p$} & \multirow{2}{*}{$\begin{array}{c}\text { Collinearity } \\
\text { VIF }\end{array}$} \\
\hline & $\beta$ & $S E$ & & & & \\
\hline Intercept & 4364.17 & 332.66 & & 13.12 & $<.000$ & \\
\hline $\begin{array}{l}\text { Log Adult } \\
\text { Rejection } \\
\text { Sensitivity } \\
\text { Questionnaire }\end{array}$ & -742.51 & 119.28 & -.537 & -6.23 & $<.000$ & 1.03 \\
\hline $\begin{array}{l}\text { Square Root \# } \\
\text { Deployments }\end{array}$ & -367.33 & 169.69 & -.187 & -2.17 & .033 & 1.03 \\
\hline
\end{tabular}

Note: Adjusted $R^{2}=.341, F=24.57, p<.001$.

significantly related to relationship satisfaction. Previous research noted that military deployments were associated with poorer marital outcomes (Karney \& Crown, 2007; Sheppard et al., 2010). The present study adds to that literature by suggesting that both rejection sensitivity and the number of deployments were negatively related to relationship adjustment.

While this research documents rejection sensitivity among military spouses, it is uncertain how much these findings would vary across military units that differ in organizational structure and mission assignments. In addition, this sample was not representative of older military spouses. Future research is needed to address how different military units, diverse cultures and family structures are impacted and how couples who have divorced following deployments have experienced rejection sensitivity. Nonetheless, this research has provided further support for the association between rejection sensitivity and relationship adjustment.

\section{Acknowledgements}

We are indebted to the military family members who participated in this study. We would also like to thank Drs. Martha Pelaez, Gary Schulman, Anthony Greene and Henry Soper for their assistance with this research and Lissette Medina for her assistance with this manuscript.

\section{REFERENCES}

Burrell, L., Adams, G., Durand, D., \& Castro, C. (2006). The impact of military lifestyle demands on well-being, Army, and family outcomes. Armed Forces and Society, 33, 43-58. doi: $10.1177 / 0002764206288804$

Busby, D., Christensen, C., Crane, D., \& Larson, J. (1995). A revision of the Dyadic Adjustment Scale for use with distressed and non-distressed couples: Construct hierarchy and multidimensional scales. Journal of Marital and Family Therapy, 21, 289-308. doi:10.1111/j.1752-0606.1995.tb00163.x

Call, V., \& Teachman, J. (1991). Military service and stability in the family life course. Military Psychology, 3, 233-251. doi: $10.1207 / \mathrm{s} 15327876 \mathrm{mp} 03044$

Card, J. (1983). Lives after Vietnam: The personal impact of military service. Lexington, MA: D. C. Heath.

Cohen, J. (1992). Statistical power analysis. Current Directions in Psychological Science, 1, 98-101.

Crane, D., R., Allgood, S., Larson, J. H., \& Griffin, W. (1990). Assessing marital quality with distressed and nondistressed couples: A comparison and equivalency table for three frequently used measures. Journal of Marriage and the Family, 52, 87-93.

doi: $10.2307 / 352841$ 
Derogatis, L. (1984). The derogatis stress profile DSP®: Preliminary administration \& scoring manual. Baltimore, MD: Clinical Psychometric Research.

Downey, G., Berenson, K. R., \& Kang, J. (2006). The adult rejection sensitivity questionnaire (ARSQ). Columbia University.

Downey, G., \& Feldman, S. (1996). Implications of rejection sensitivity for intimate relationships. Journal of Personality and Social Psychology, 70, 1327-1343. doi:10.1037/0022-3514.70.6.1327

Downey, G., Freitas, A., Michaelis, B., \& Khouri, H. (1998). The self-fulfilling prophesy in close relationships: Rejection sensitivity and rejection by romantic partner. The Journal of Personality and Social Psychology, 75, 545-560.

doi: $10.1037 / 0022-3514.75 .2 .545$

Eysenck H., \& Eysenck, S. (1964). Eysenck personality inventory. San Diego, CA: Educational Testing Service.

Feldman, S., \& Downey, G. (1994). Rejection sensitivity as a mediator of the impact of childhood exposure to family violence on adult attachment behavior. Development and Psychopathology, 6, 231-247.

Fincham, F., \& Bradbury, T. (1992). Assessing attributions in marriage: The relationship attribution measure. Journal of Personality and Social Psychology, 62, 457-468. doi:10.1037/0022-3514.62.3.457

Freitas, A., \& Downey, G. (1998). Resilience: A dynamic perspective. International Journal of Behavioral Development, 22, 263-285. doi:10.1080/016502598384379

Frey-Wouters, E., \& Laufer, R. (1986). Legacy of a war. Armonk, NY: M. E. Sharpe Press.

Gimbel, C., \& Booth, A. (1994). Why does military combat experience adversely affect marital relations? Journal of Marriage and the Family, 56, 691-703. doi:10.2307/352879

Karney, B., \& Crown, J. (2007). Families under stress: An assessment of data, theory, and research on marriage and divorce in the military. Washington, DC: National Defense Research Institute.

Laufer, R, \& Gallops, M. (1985) Life-course effects of Vietnam combat and abusive violence: Marital patterns. Journal of Marriage and the Family, 47, 839-853. doi:10.2307/352328

Levy, M., \& Davis, K. (1988). Love styles and attachment styles compared: Their relations to each other and to various relationship characteristics. Journal of Social and Personal Relationships, 5, 439-471. doi: $10.1177 / 0265407588054004$

Mischel, W., \& Ayduk, O. (2002). Self-Regulation in a cognitiveaffective personality system: Attentional control in the service of the self. Self and Identity, 1, 113-120. doi: 10.1080/152988602317319285

Pittman, J., Kerpelman, J., \& McFadyen, J. (2004). Internal and external adaptation in army families: Lessons learned from Operations Desert Shield and Desert Storm. Family Relations, 53, 249-260. doi:10.1111/j.0197-6664.2004.0001.x

Purdie, V., \& Downey, G. (2000). Rejection sensitivity and adolescent girls' vulnerability to relationship difficulties. Child Maltreatment, 5, 338-349. doi:10.1177/1077559500005004005

Sheppard, S., Malatras, J., \& Israel, A. (2010). The impact of deployment on U.S. military families. American Psychologist, 65, 599-609. doi:10.1037/a0020332

Spanier, G. (1976). Measuring dyadic adjustment: New scales for assessing the quality of marriage and similar dyads. Journal of Marriage and the Family, 38, 15-28. doi:10.2307/350547

Spanier, G. (1986). This week's citation classic. Classic Citation, 5152.

Stellman, J., Stellman, S., \& Sommer, J. (1988). Social and behavioral consequences the Vietnam experiences among American Legionnaires. Environmental Research, 47, 129-149. doi:10.1016/S0013-9351(88)80038-0

Watson, D., \& Friend, R. (1969). Measurement of social evaluative anxiety. Journal of Consulting and Clinical Psychology, 33, 448457. doi: $10.1037 / \mathrm{h} 0027806$ 